\title{
Physical-Organic Chemistry: A Swiss Army Knife
}

\section{Citation}

Whitesides, George M. 2015. "Physical-Organic Chemistry: A Swiss Army Knife." Israel Journal of Chemistry 56 (1) (November 30): 66-82. Portico. doi:10.1002/ijch.201500061.

\section{Published Version}

10.1002/ijch.201500061

\section{Permanent link}

http://nrs.harvard.edu/urn-3:HUL.InstRepos:29914188

\section{Terms of Use}

This article was downloaded from Harvard University's DASH repository, and is made available under the terms and conditions applicable to Open Access Policy Articles, as set forth at http:// nrs.harvard.edu/urn-3:HUL.InstRepos:dash.current.terms-of-use\#OAP

\section{Share Your Story}

The Harvard community has made this article openly available.

Please share how this access benefits you. Submit a story.

\section{Accessibility}




\title{
Physical-Organic Chemistry: A Swiss Army Knife
}

\author{
George M. Whitesides \\ Department of Chemistry and Chemical Biology \\ Harvard University \\ Cambridge MA 02138 USA
}

\begin{abstract}
"Physical-organic chemistry" is the name given to a subfield of chemistry that applies physical-chemical techniques to problems in organic chemistry (especially problems involving reaction mechanisms). "Physical-organic" is, however, also a short-hand term that describes a strategy for exploratory experimental research in a wide range of fields (organic, organometallic, and biological chemistry; surface and materials science; catalysis; and others) in which the key element is the correlation of systematic changes in molecular structure with changes in properties and functions of interest (reactivity, mechanism, physical or biological characteristics). This perspective gives a personal view of the historical development, and of possible future applications, of the physical-organic strategy.
\end{abstract}

\section{Introduction}

"Physical-organic chemistry" is not really about physical chemistry, organic chemistry, or even chemistry. It is a strategy for the design of programs in experimental scientific researchadmittedly, a strategy most highly developed for research involving organic molecules as components - that offers a general, and remarkably versatile, method for tackling complex problems. The idea underlying "physical-organic" design is simple: it requires a system that enables one to carry out similar physical measurements on a set of structurally related compounds, to change the structures of these compounds systematically and by design, and to infer the nature of processes of interest from changes in these physical measurements with structure. (It thus differs from physical chemistry, in which one might make a series of measurements at different temperatures, or focus on detailed spectroscopic measurements, but on a single compound.) There is, of course, no sharp line between examining how the variation in an observable correlates with changes in structure, and focusing on the detailed examination of that observable in a single structure (or small group of structures). The physical-organic approach is most useful when sets of structurally related compounds are available through synthesis or isolation (thus its particular utility in studies of organic, organometallic, and biological molecules). It does not exclude programs that include variations in environment (temperature, $\mathrm{pH}$, solvent character), but its emphasis is on the relationships between the structures of molecules of interest and the properties of those molecules. Its beauty is that within in the constraints of certain assumptions - it provides a simple and conceptually transparent way to isolate the influence of molecular structure on a property or function of interest.

Assume that one is interested in a problem in which available — and relevant—physical tools are either limited or cumbersome. Examples of such problems in which we have been interested include the mechanism of formation of Grignard reagents ${ }^{[1-3]}$; the wetting of (and adhesion to) the surfaces of organic solids presenting complex functional groups by water ${ }^{[4-6]}$, cells ${ }^{[7,8]}$, or other organic molecules ${ }^{[9,10]}$; the mechanism of tunneling of electrical charge through nanometer- 
thick organic films ${ }^{[11,12]}$; and the role of water in biology ${ }^{[13]}$. These, and in fact most, scientific problems dealing with complex reality are almost always too complicated to understand using only the information generated by a single, simple approach. As an experimentalist, then, one has a choice: one can take a specific system, and study it in great detail, hoping that "depth" will yield understanding; or one can take a series of related compounds, and look for trends. Physicalorganic chemistry is based on the latter strategy. (By analogy, when exploring a new continent, one generally wants to know first where the rivers and mountains are, and only then the details of the local terrain.) It may, for example, be impossibly difficult to understand entirely how cyanide ion, dissolved in a complex solvent containing salts, reacts with methyl chloride; it is, however, practical to ask how the reaction(s) of organic chlorides - whatever its (or their) mechanism(s) respond(s) to a broad range of changes in the structure of the reactants. What happens when one changes methyl chloride to ethyl-, propyl-, isopropyl-, t-butyl-, benzyl-, and phenyl chlorides? What happens with this series when one exchanges the cyanide ion for a fluoride, chloride, bromide, or iodide ion?

This strategy seems self-evident, but it is not. It says, in essence, that understanding the details of the interaction between a cyanide ion and an organic halide dissolved in a complex fluid medium may be a problem that is too difficult to be tractable, but that understanding one aspect of the problem - how the reaction rate responds to changes in the structure of one of the reactants - is both tractable, and useful in its potential to suggest details of the overall reaction mechanism. It also allows for the discovery of analogies: for example, variations in rate of reaction with the structure of organic halides may be similar for the cyanide and bromide ions, or different, and either answer is instructive; the qualitative observation of similarity or difference can be extremely instructive in formulating mechanisms, in designing systems of reactions for synthesis, and in drawing inferences about very complicated processes in organometallic and biological chemistry.

The physical-organic approach to a complex problem in reactivity is based on the idea that a relatively tractable survey of trends in reactivity (or in a spectrum of reactivities) with the structures of the reactants may be easier to interpret than Talmudic studies of the absolute values of (for example) rate constants for a specific, limited pair of reactants. Based on this kind of idea, physical-organic studies have allowed the construction of a series of empirical rules (or "rules of thumb") about organic reactivity. These rules have been immensely useful in guiding synthesis, and they have served as the basis for broadly accepted postulates about "mechanism."

Physical-organic strategies are also a kind of garden path down which one can stroll, happily ignoring both the real complexity of turns in the path, and ambiguities in the destination it reaches (or seems to reach). Taking solvolysis as one example: physical-organic studies led to the useful, empirical, identification of trends in part of the problem - the part concerning relations between structure and reactivity - that could be studied easily. They also almost entirely ignored - until the brilliant work of John Brauman and others ${ }^{[14-16]}$ - the contribution of solvent to that reactivity, the disambiguation of contributions of solvent and reactants to many parts of the problem, and the role of enthalpy (which is believed to be relatively well understood in many organic processes) relative to that of entropy (which is not). To a significant extent, mechanistic and synthetic chemistry have co-evolved a view of organic reactivity that can be said to ignore large parts of the contribution of the medium. This selective vision has 
complicated the extrapolation of processes - especially ones having free energies that are small relative to RT, such as molecular recognition - from organic to aqueous media (and has, thus, hindered very practical problems in biochemistry and medicinal chemistry such as the problem of so-called "rational ligand design").

Is the kind of selective blindness from which physical-organic chemistry sometimes suffers (as, indeed, every approach to experimental science suffers) a problem? The answer depends upon one's needs, and on one's point of view. For many circumstances, empirical correlations are all that is required. From a more fundamental point of view, they can be both stimulating and immensely useful in outlining the solution to a problem in mechanism or prediction-or positively misleading. One of the obvious, remarkably subtle, and increasingly under-appreciated characteristics of chemistry (and, of course, many other areas of condensed matter science) is that both entropy and enthalpy can contribute to any process (Eqs. 1 and 2, the same equation expressed in units of $\mathrm{J} \mathrm{mol}^{-1}$ and $\mathrm{J} \mathrm{mol}^{-1} \mathrm{~K}^{-1}$, respectively) and that ultimately the second law of

$$
\begin{aligned}
& \Delta G=\Delta H-T \Delta S \\
& \frac{\Delta G}{T}=\frac{\Delta H}{T}-\Delta S
\end{aligned}
$$

thermodynamics (of which eg. 2 is one form) rules. Ignoring the details of interactions between reactants and media leads to a tendency to attribute effects resulting from those interactions to imaginary influences of electronic structure and steric effects. This kind of misattribution can profoundly muddle ideas about mechanism, and lead to assumptions that can sometimes point in the wrong direction, as, for example, the enormously successful - by almost any measure - body of work on non-covalent self-assembly in organic solvents ${ }^{[17,18]}$. (The significant failure of this work was - and to an extent remains - its optimistic assumption that studying the self-assembly of organic molecules in methylene chloride solution - a form of self-assembly often mediated by highly directional hydrogen bonds, or large ion-dipole effects, and one in which solvent effects seem to be relatively simple - illuminates self-assembly resulting from the hydrophobic effect in water $^{[19]}$.)

You get out what you put in: if, in a subject as complicated as organic reaction mechanisms, you assume that solvent is not important, and that enthalpy is much more important than entropy, you will almost always be able to interpret your results in a way that is consistent with those assumptions (... and, particularly, if you think of free energy, $G$, as just another form of enthalpy, H.)

So: physical-organic chemistry is an enormously useful tool for isolating one factor-the role of organic structure on processes involving organic molecules - in a multifactorial problem. It is wonderfully instructive and practical for survey work; it can be used-with sometimes more difficult thermodynamic, structural, spectroscopic, and computational/theoretical studies - to guide much more sophisticated work that moves closer to an often inconveniently complicated truth. It is too fragile, as a stand-alone structure, to resolve difficult problems completely by itself. 


\section{History}

Origins. Physical-organic chemistry was an invention of the mid- $20^{\text {th }}$ century, with an epoch (pre-WW II) that started by introducing the revolutionary idea that physical-chemical measurements could be instructive when applied to complicated organic reactions, and continued (post-WW II) by developing a broad range of applications for the flood of catalytic, synthetic, spectroscopic, computational, and theoretical methods that came, at least in part, from the technologies developed for other purposes during the $\operatorname{war}^{[20]}$. It initially focused almost exclusively on studies of organic reactivity, with conventional methods of kinetics augmented by the exquisite methods of separation provided by HPLC and GC, and by determination of molecular structures by NMR, IR, UV/Vis, and mass spectroscopy, by x-ray crystallography, by isotopic labeling, by stereochemistry, and by molecular orbital theory. The chemists who contributed to this are too many to include adequately in even a partial list, but among them were Ingold, Hughes, Winstein, Bartlett, Swain, Bloch, Roberts, Arigoni, Doering, and others. Among the triumphs of this period were the development of countless, more-or-less predictive, correlations between structure and reactivity, the inference and identification of short-lived intermediates (e.g., non-classical carbonium ions, carbenes, free radicals, benzyne, singlet oxygen, and many others), and the description of many types of processes that broke and formed covalent bonds (e.g., reaction mechanisms, from "simple" $\mathrm{S}_{\mathrm{N}} 2$ processes to so-called "nomechanism" processes such as the Diels-Alder reaction, the mechanism of action of triose phosphate isomerase ${ }^{[21]}$, and the processes underlying olefin metathesis ${ }^{[22]}$ ). Physical-organic chemistry freed organic chemistry from the requirement that a molecule must have sufficient stability to be put into a bottle in order to be identified and studied. Molecular orbital (and later, extended MO) theory provided a framework for thinking about concepts such as aromaticity, an understanding of orbitals, and some appreciation of how difficult it can be to correlate the early, deeply entrenched concepts of localized bonds, with the reality of delocalization (a realization later reinforced by density functional theory).

These studies of structure and reactivity were very successful, and have become part of the intellectual (if empirical) foundation of the revolution in organic synthesis that occurred in this period.

Diffusion into Other Problems. As the concepts and techniques of organic chemistry began to spread into new fields (e.g., organometallic chemistry, bioorganic chemistry and enzymology, polymer science, surface science, and materials science), physical-organic chemistry incorporated new ideas, and continued to contribute to these newly minted and rapidly developing fields. The range of the interests of groups that effortlessly incorporated the principles of physical-organic chemistry into their research spanned all of these fields, and other, newer ones. Although it is again impossible to give adequate credit to individuals, work in organometallic chemistry that fused organic and inorganic chemistry (with brilliant work by Bergman, Grubbs, Muetterties, Tebbe, Parshall and others at DuPont Central Research ${ }^{[23]}$, and many others elsewhere) and bioorganic chemistry (with quite different, but equally remarkable studies by Abeles, Jencks, Walsh, Knowles, Stubbe, and many others - beautifully described in Walsh's book ${ }^{[24]}$ ) illustrates the quality of such efforts. 
One sometimes hears the statement "Physical-organic did its thing, and died." Nothing could be further from the truth. Physical-organic chemistry developed a versatile set of techniques using the relatively well-defined problems posed by organic synthetic methods (both academic and industrial), and then moved to nearby neighborhoods to apply those techniques in new fields. It is, in fact, now impossible to find a subject that uses organic chemistry or organic molecules that does not, in some way, use physical-organic chemistry.

\section{Characteristics of "Phys-Org" as a Tool in Molecular Chemistry}

Physical-organic chemistry has, thus, developed as an almost universal tool with which to survey certain characteristics (trends relating structure and reactivity, possible/plausible reaction pathways, possible/plausible structures of short-lived intermediates, and sensitivities to environmental factors) of reactions that involve organic groups. It is the basis of "arrowpushing," (a very valuable accounting method much used in some areas of organic chemistry, but not to be confused with the fundamentally different conceptual activity of describing "reaction mechanisms"). It is especially valuable in organic and organic-related fields because it relies on interpreting trends in a series of reactions involving related structures as a method of characterizing these reactions, rather than on studying and interpreting detailed measurements of a single reaction. Organic chemistry is especially appropriate for these kinds of studies because it is uniquely practical to synthesize series of structurally related organic compounds, and much more difficult to do so with many types of inorganic, macromolecular, and surface species.

An Empirical Tool. Physical-organic chemistry is primarily an empirical tool, one based largely on comfortable (if not necessarily correct) correlations founded in free energy or enthalpy (rather than entropy). So, for example, ideas such as "aromaticity" (as the basis for the stability - as opposed to the reactivity — of certain types of highly unsaturated compounds), the "inductive effect" (as the basis for differences in acidity in organic acids), and delocalization (as an explanation for the barrier to rotation around the carbon-nitrogen bonds of amides) are all firmly embedded in the instruction provided to undergraduate chemists in introductory courses. The marvelous book - a truly unique contribution to the field - by Anslyn and Dougherty illuminates many of these subjects, and points especially clearly to the problems that arise when one tries to rationalize as enthalpic an effect that is due to entropy (and not necessarily even the entropy of the reacting molecule) in a strongly interacting solvent ${ }^{[25]}$. (It is worth noting again that water is a strongly interacting solvent, and that physical-organic chemistry has been substantially less useful than one might hope in activities such as designing tight-binding ligands for proteins, or rationalizing protein folding.)

The Right Answers for the Wrong Reasons. That said, for whatever its weaknesses, physicalorganic chemistry is often eerily correct in its rationalizations and predictions, albeit sometimes for the wrong reasons. Chemistry is, in fact, an empirical science, founded on observing structures and reactions, and on forming hypotheses connecting, and rationalizing empirical correlations between the two. There is no intrinsic problem with an intellectual structure of this sort; it occurs throughout the history of every area of science: Hückel MO theory ${ }^{[26]}$ provides another example in which the results are substantially better than they might be expected to be, given the limitations of the theory ${ }^{[27]}$. The availability of ever-improving theory, and of highperformance computing, (and also of more familiar subjects, such as automated calorimetry and 
x-ray crystallography) are beginning to clarify some of these empirically useful, but not necessarily correct, approximations.

Strengths and Weaknesses. Physical-organic chemistry has both. I would list five characteristics as strengths: i) It is a superb tool for systematization and correlation, and has been particularly good at using inferences drawn from simple processes (or that seem simple, but are not e.g., the ionization of structurally uncomplicated carboxylic acids in water and polar solvents) to rationalize or predict properties of much more complicated processes in organic chemistry, in organometallic chemistry, in biochemistry, in materials science, and in other fields. ii) It has been invaluable in providing a predictive structure for correlations connecting a range of processes and subjects - from organic structure and organic reactivity in organic synthesis, to relations connecting the molecular-level structures of molecules and the macroscopic properties of materials incorporating those molecules. iii) It has used molecular orbital theory (from Hückel theory, through molecular dynamics, to DFT) extraordinarily successfully in helping to rationalize the reactivities and properties of very complex materials and processes. iv) It has provided an intellectual structure that could be used to correlate physical information (molecular and electronic structure), results from simulation and theory, and observations of reactivity, and also to suggest new directions for exploratory studies. v) It is particularly accurate when the characteristic being considered correlate strongly with enthalpy rather than entropy.

I would also suggest five matching weaknesses: i) "Correlation", as a strategy, is both a strength and a weakness; it is not a "fundamental" approach to science, and it is distressingly easy to confuse "cause" and "correlation". Although science is ultimately empirical, and although physical-organic chemistry is a splendid tool with which to guide the collection of information to test hypotheses, it ultimately rests on the availability of experimental data (unlike, for example, quantum mechanics, in which theory has often outstripped experiment.) ii) It tends to ignore entropic factors in constructing hypotheses, and the experimental difficulty and unpopularity of thermochemistry in "modern" curricula has not strengthened the thermodynamic foundations of the field. It is, in fact, much easier to think about energy (enthalpy) than entropy, and to assume that free energy is dominated by enthalpy, than it is to balance enthalpy and entropy in building hypotheses and theory. In some cases, this enthalpy-biased approach is - often by accidentsuccessful. In others - and especially when solvent and solvation are an important part of whatever processes being considered-physical-organic correlations can be quite wrong. iii) Historically, it has tended to avoid even simple mathematics. By background, physical-organic chemists tend to approach science through synthesis and measurement rather than through theory. The subjects that they study, by contrast, are often very complicated, and these subjects require a mathematically sophisticated treatment if they are to be described analytically. As the divisions between fields of chemistry change, and as computational methods make even very sophisticated mathematical methods accessible, this weakness is being pushed aside. That said, the statistical methods that are required to think about entropy-dominated structures and processes are not second nature to most of those in the field. iv) It has, so far, tended to give results that are misleading when considering solvent effects, where many weak interactions sum to an observed result. Processes occurring in water, and especially in biochemistry (for example, the hydrophobic effect and molecular recognition ${ }^{[13,19]}$ ) have been especially problematic. Organometallic chemistry (where multiple parallel processes may compete) and polymer chemists (where there are often a multiplicity of conformations) can also be problematic. Theory and new, specialized computational methods are, again, making alternative approaches possible, 
but it is hard to argue that we understand organic chemistry in water. v) The physical-organic chemistry of complex systems at the border between chemistry and condensed matter sciencematerials science, heterogeneous catalysis, dynamic and dissipative systems — still remain to be developed.

\section{Our Uses and Abuses of Physical-Organic Chemistry.}

We — my colleagues and I — have used physical-organic chemistry profitably across a wide range of different subjects. In some cases the use has been casual; in others, much more detailed. Our studies have often been designed to explore subjects that have previously been less explored, and for this type of work, approaches based on physical-organic chemistry have been spectacularly useful (for us). Let me give some examples, primarily to illustrate the range of problems to which this subject can contribute useful techniques. I emphasize that our work has always been only a part of the invention / discovery of any subject, and that many others have also contributed. To save space (with the excuse that this paper is a personal account rather than a review), and to provide concise illustration, I discuss largely our work.

\section{Organometallic Chemistry.}

Organocopper(I) Chemistry. One of our first areas of research in organometallic chemistry involved studies of the reactivity of organocopper(I) compounds ${ }^{[28]}$. These compounds were moderately thermally unstable, and an outstanding mechanistic problem (especially at the beginning of transition-metal $\sigma$-bonded organometallic chemistry) was to determine whether their thermal decomposition (which generated mixtures of compounds, including a number with carbon-carbon bonds) involved a concerted pathway, or processes generating organic free radicals. A very simple experiment-involving the decomposition of stereochemically defined propenylcopper(I) - provided an example of the ability of physical-organometallic chemistry to solve a tricky problem in mechanism (Eq. 3). The rate of inversion of configuration of propenyl radical had been established to be approximately $10^{12} \mathrm{~s}^{-1}$; since the decomposition proceeded

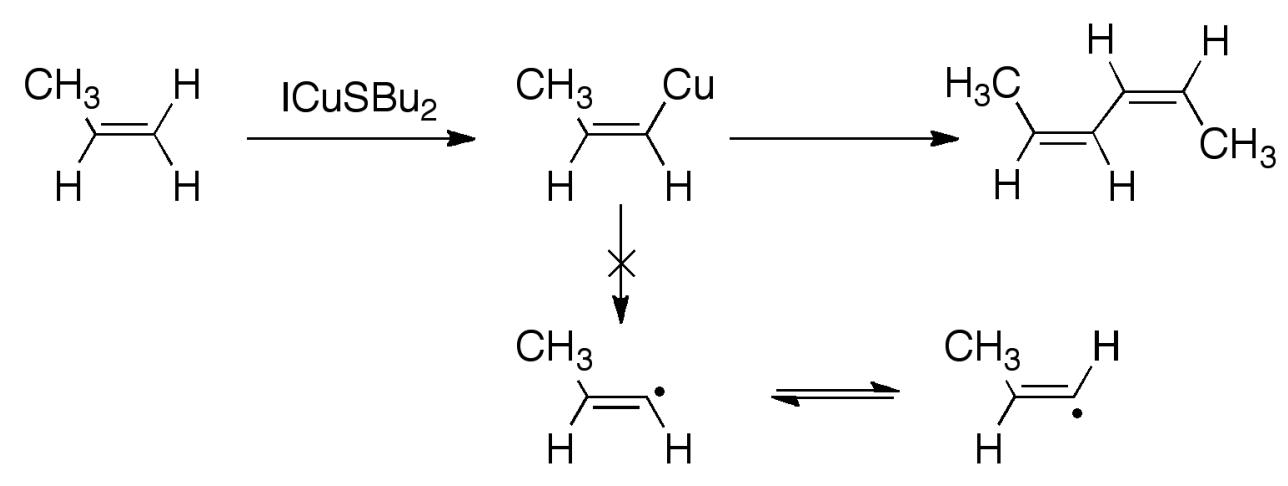

(Eq. 3)

with retention of configuration, it was easy to establish that free radicals could not be involved in these decompositions ${ }^{[29]}$. This example illustrates the ability of stereochemistry to be a "clock" operating with femto-second resolution - a technique highly developed throughout physicalorganic chemists. 
Intramolecular Reactions in Organoplatinum(II) Compounds. We were also interested in the mechanistic pathways followed in the decomposition of organoplatinum(II) compounds (as models for processes occurring on the surface of heterogeneous platinum catalysts). These studies $^{[30-34]}$, along with parallel, beautiful, studies by Bergman ${ }^{[35]}$, played a useful role in establishing the facility with which late transition metals could cleave (either intra- or intermolecularly) unactivated aliphatic $\mathrm{C}-\mathrm{H}$ bonds. These studies were extensive, but involved conceptually straightforward examinations of products: the characterization of C-H bonds by examining the shuffling of deuterium in isotopically labeled species using NMR or mass spectroscopy ${ }^{[30]}$. Among the interesting outcomes of this work was the realization that cleavage of unactivated $\mathrm{CH}$ bonds (e.g., of methane) proceeded very rapidly by reaction with $\operatorname{Pt}(0)$ centers in solution (Eq. 4).

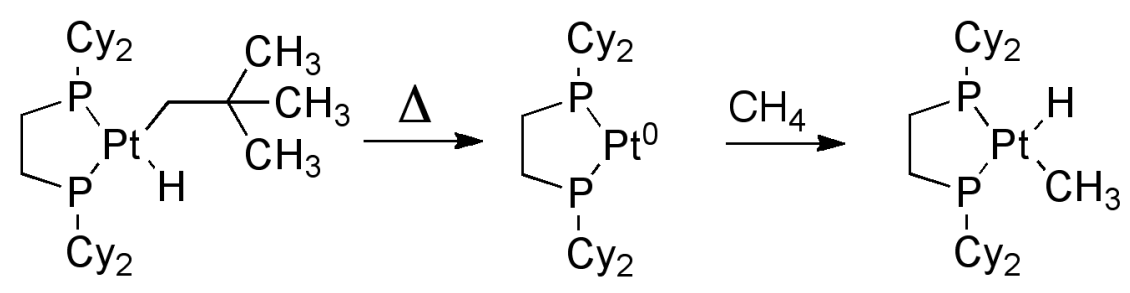

$$
\text { Cy = cyclohexyl }
$$

Surface Organometallic Chemistry: Alkyl Groups on the Surface of Platinum. Since most reactions of alkanes activated by platinum are heterogeneous (with the platinum often supported as a nanoscale colloid on silica or alumina), we obviously wished to compare reactivities in solution with those on the surface of a supported platinum(0) particle. Again, straightforward physical-organic approaches provided an approach to a complicated problem. Reaction of dialkyl $(1,5)$ cyclooctadieneplatinum(II) compounds with supported platinum( $(0)$ in the presence of $\mathrm{H}_{2}$ proceeded by transferring the "Pt(II) $\mathrm{R}_{2}$ " moiety to the $\mathrm{Pt}(0)$ surface, (with the reaction of cyclooctadiene to cycloctane) where it formed surface platinum alkyls with well-defined structures. Isotopic labeling enabled us to follow the subsequent reactions (particularly reactions involving $\mathrm{C}-\mathrm{H}$ bonds) of these surface alkyls - reactions, rearrangements, isotopic exchange reactions, and others — on the surface ${ }^{[30]}$.

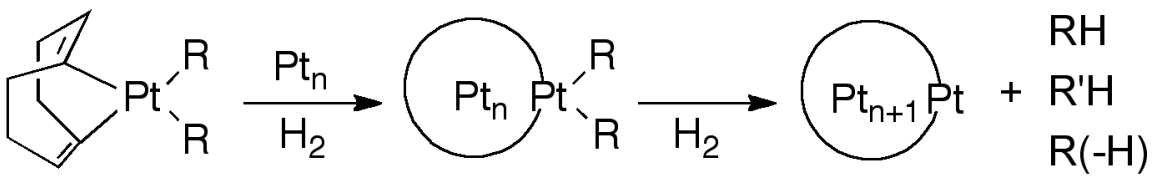

The Mechanism of Formation of Grignard Reagents. A conceptually related set of studies $^{[1,2,36-39]}$, with entirely different mechanistic problems, concerned the mechanism of formation of Grignard reagents by the reaction of organic halides with metallic magnesium in ethereal solvents. Studies of stereochemistry and product revealed that this heterogeneous reaction proceeded predominantly by electron transfer ${ }^{[36-39]}$, followed by reaction of the resulting organic free radical with the surface of magnesium, and made it possible to define some of the characteristics of the corrosion reaction that removed magnesium atoms from the bulk metal. (It thus used vpc to determine important elements of a very rapid reaction occurring at a reactive metal surface.) 


\section{Surface Science.}

Connecting Molecular-Level and Macroscopic Properties: Wetting and "Materials by Design." "Polyethylene Carboxylic Acid" and Self-assembled Monolayers. Much of our work in surface science has involved organic surfaces, both of "real" materials (e.g., polyethylene film) and of synthetic materials (e.g., self-assembled monolayers, or SAMs). These studies began with examinations of polyethylene film, onto whose surface had been introduced carboxylic acid groups (by oxidation with chromic acid in sulfuric acid) ${ }^{[40,41]}$; we called the material generated by this procedure "polyethylene carboxylic acid," or "PE- $\mathrm{CO}_{2} \mathrm{H}$," and used it as a model system with which to develop many of the techniques that we subsequently applied to SAMs ${ }^{[12]}$. Much of surface science, when we started this work, was dominated by careful, expensive, and often slow studies of reactions of small molecules with carefully aligned and polished single crystals of transition metals in ultrahigh vacuum. Our interest was in "organic" surfaces for three reasons: i) They were more relevant to biochemistry, and to the materials properties of organic polymers;

ii) They were much easier to work with experimentally, since they were easy to make, and because their low-free-energy surfaces resisted contamination, even in ambient conditions; iii) It was straightforward to apply physical-organic methods to characterize structures and processes on their surfaces, rather than having to infer results obtained by using more difficult and expensive surface spectroscopies. An example involved following reactions that occurred on the surface of $\mathrm{PE}-\mathrm{CO}_{2} \mathrm{H}$. Since we knew that a carboxylic acid was more polar (and more hydrophilic) than a carboxylic acid ester, we could easily follow the interconversion of the acid and ester simply by following the wetting of the surface by water (sometimes as a function of $\mathrm{pH})^{[42]}$. We usually carried out initial characterization of a surface simply by applying a drop of water from a fingertip to the surface of interest, and observing whether it formed a bead, or spread (Fig. 1) ${ }^{[43]}$. "Simplicity" is often a major advantage in science!

One of the strong motivations to develop self-assembled monolayers (SAMs) having the structure AuSR (where "Au" represents the surface of a smooth, evaporated gold film) was again based on physical-organic considerations. Because it was straightforward to make organic molecules of the structure $\mathrm{HS}\left(\mathrm{CH}_{2}\right)_{\mathrm{n}} \mathrm{X}$ (where $\mathrm{X}$ was a wide range of organic functional groups), it was also possible to make a wide range of organic surfaces that differed both in the characteristics provided by " $\mathrm{X}$ ", and in those originating in the thickness of the polymethylene layer $\left(\mathrm{CH}_{2}\right)$ n. These two degrees of freedom made it possible to examine trends connecting properties (wettability, adhesion, and so on) with molecular structure (Fig. 2) ${ }^{[4-10]}$.

Charge Tunneling across Self-assembled Monolayers. A final example of the ability of physical-organic chemistry to illuminate processes that are influenced by unidentified variables involves the study of charge transport by quantum tunneling across self-assembled monolayers. We spent a substantial amount of time developing an appropriate junction with which to study this system, and we have described the final result - a junction of the form

$\mathrm{Ag}^{\text {ts }} / \mathrm{A}\left(\mathrm{CH}_{2}\right)_{\mathrm{n}} \mathrm{M}\left(\mathrm{CH}_{2}\right)_{\mathrm{m}} \mathrm{T} / / \mathrm{Ga}_{2} \mathrm{O}_{3} / \mathrm{EGaIn}$ - in a number of papers (Fig. 3) ${ }^{[44-48]}$. What has made this system so instructive has been the ease with which the organic structure of the molecules in the SAM can be changed. The "anchoring group" A can be S-, ${ }^{-} \mathrm{O}_{2} \mathrm{C}-$, or acetylene ${ }^{[49,50]}$; the "middle" group $\mathrm{M}$ can be any one of a number of well-understood organic groups (e.g., amide, phenyl, ether $)^{[51]}$, and the "terminal" group T can have even wider latitude ${ }^{[52-56]}$. Studies of this system, when combined with outstanding work by Cahen ${ }^{[57]}$, Nijhuis ${ }^{[58]}$, Frisbie $^{[59]}$, and a number 
of others, have been most useful in detailing the connection between the structure of the SAM and the tunneling current. The particular advantage of the physical-organic approach that we have used in much of our work (as opposed to the complementary, equally instructive, but more focused studies by Cahen, Frisbie, and others), has been the ability to look for trends in tunneling current as a function of the composition of the groups A, M, and T, as well as with the spacing of these groups relative to the electrodes (as determined by the lengths of the poly(methylene) spacers $n$ and $m$ ).

Self-Assembly. One of the most interesting changes in organic chemistry in the last 20 years - a change based, in large part, on the growing importance of biology - has been an increased focus on understanding and using molecular self-assembly ${ }^{[60]}$ and in understanding the chemistry of weak and kinetically labile bonds. Historically, organic chemistry has focused on the synthesis of molecular compounds formed through kinetically stable covalent bonds. These compounds are, of course, stable (or metastable) under ambient conditions, and appropriate for uses that require a structure (or at least composition and atomic connectivity) that does not change with time. By contrast, many of the most important classes of compounds and structures in biology form by self-assembly based on noncovalent bonds (or interactions) whose strength is sufficiently low that they can break and reform at room temperature. Examples include folded proteins and nucleic acids, multi-protein complexes, lipid membranes, and many others. Kinetically labile bonds (e.g., disulfides in the presence of thiols) are also important.

We were part of a group of investigators who set out to begin to explore molecular self-assembly and non-covalent organic chemistry; these investigations were often based on physical-organic principles, and had as an early example the important studies by Lehn of the chemistry of crown ethers ${ }^{[61]}$. Studies of metal-based systems connected by coordination bonds that were less strong than conventional organic covalent bonds, but substantially stronger than those characteristic of biological systems, have become an important theme in organic chemistry. This theme-strongly influenced by physical-organic designs - arguably, led to the much more elaborate structures connected through coordination compounds prepared by Lehn ${ }^{[62]}, \mathrm{Stang}^{[63]}$, Sauvage ${ }^{[64]}$, Wuest $^{[65]}$, and many others, and ultimately to metal-organic frameworks ${ }^{[66]}$, or MOFs). We, also, found the ideas readily generated by physical-organic designs to be useful. Molecular selfassembly - especially in the able hands of Bert Meijer - is only now coming into its own as a branch of materials science ${ }^{[67,68]}$.

Interestingly, one of the conceptual foundations of the field of non-covalent self-assembly, from its inception, has been the implicit assumption that studying self-assembly in these types of systems would be instructive in thinking about self-assembly in water, and thus in biochemistry. Admittedly, self-assembly in methylene chloride might seem different than self-assembly in water, but if one conveniently ignores the enormous differences in these solvents, results obtained with one might be hoped to be relevant to those in the other. In retrospect, this hope was not a realistic one. It ignored fundamental differences between processes in organic solvents and processes in water, the different roles of enthalpy, entropy, and interactions with solvent, and illustrates a weakness of physical-organic chemistry: that is, if there is an unexamined assumption, things can go wrong. In this case, the doubtful assumption dealt primarily with water. Many organic solvents are similar, and interact relatively weakly with the materials they dissolve. Water, by contrast, forms intricate networks, in which entropy and enthalpy are both 
important, and the free energy of these networks - free energies that are different in every caseare centrally important to any process proceeding in water, since these processes restructure the networks ${ }^{[19,69]}$. In fact, we conclude that, in the systems we have studied carefully, changes in the free energy of the water solvating the interacting molecules before and after their association can dominate the free energy of the self-assembly (and more specifically, of protein-ligand association).

Self-Assembly: Derivatives of Melamine and Cyanuric Acid. Melamine and cyanuric acid combine to form a hydrogen-bonded solid with very high stability (Fig. 4) ${ }^{[70]}$. Both melamine and cyanuric acid are easily modified, and these modifications provide the basis for a very simple system with which to study self-assembly, both in molecules in solution, and in the solid state $^{[71-75]}$.

Self-Assembled Monolayers. We have discussed self-assembled monolayers. They provide an example of the use of physical-organic principles to relate the properties of molecules to the properties of materials (especially the surfaces of materials) into which they can be incorporated (Fig. 5) ${ }^{[12]}$.

Oligovalency in Biochemistry. An instructive example of the weaknesses of physicalorganic reasoning is illustrated by studies in oligovalency. Many (perhaps even most) selfassembled structures in biology depend on multiple, cooperative interactions to achieve sufficient net strengths to hold the assembly together against Brownian agitation. Examples are the multiple hydrogen and hydrophobic bonds of folded proteins; the large areas of buried hydrophobic surface in lipid bilayers; the multiple binding sites presented by antibodies and many other biological structures, and a host of others ${ }^{[76]}$. One of our programs in this area was concerned with examining the factors that (perhaps) underlie the structure of antibodies, and the oligovalent presentation of binding sites on the surfaces of viruses (Fig. 6). This program produced a number of mechanistically interesting results, including the design of polymeric polyvalent inhibitors of the binding of influenza virus to erythrocytes that were up to $10^{9}$ more potent (per molecule of inhibitor) than monomers ${ }^{[77-79]}$. Mechanistic understanding of these systems remains, however, incomplete, in large part because of the difficulty in understanding the relationship between the structure of the inhibitor, the thermodynamics (especially the entropy) of restructuring this molecule on binding, and the (probably) dominant contribution of restructuring of water to binding ${ }^{[13]}$. Understanding the interplay between enthalpy and entropy in these systems is difficult, and there are, in fact, no tools that are currently available to do the job: although automated isothermal calorimetry (ITC) has made the separation of free energy into contributions from enthalpy and entropy enormously less onerous, these studies still require substantial concentrations and quantities of reactants to give reliable data, and are often impractical given the properties and quantities of scarce biologicals that are available for study.

Water in Biology, and the Hydrophobic Effect. Life goes on in water, and even in the interior of the cell — with very high concentrations of organic molecules and ions - the predominant molecule on a molar basis is water. Theory has led experiment in suggesting that the restructuring of the networks of water molecules in the active site of a protein, and around a lowmolecular weight ligand, influence - and, in many cases, dominate - the binding of that ligand 
and protein (Fig. 7) ${ }^{[76,80-82]}$. This view, of course, is quite different from the physical-organic concepts of "docking," "lock and key," and "protein-ligand interactions." The balance between entropy and enthalpy in these types of reactions remains to be determined, but, in a number of systems, ITC has established that either can dominate, and suggests that accurate predictions of the free energy of binding of protein and ligand (and especially of systems where large, relatively flat molecular surfaces are involved, as in protein-protein interactions) will not be (as they are not, now) predictive until both the enthalpy and the entropy of the water molecules participating in the reaction can be taken into account ${ }^{[13,83]}$. The success of specialized statistical-mechanical programs, such as Watermap ${ }^{[84-86]}$, for estimating the contributions of water to binding suggest that we may be close to new procedures in this important area, but disentangling the roles of protein-ligand contact interactions ("docking"), effective potential functions that may implicitly include contributions from water, and detailed empirical studies using calorimetry and crystallography is still work in progress.

Complexity, Simplicity, and Dissipative Processes. Physical-organic strategies have also proved very useful to us in areas far from the historical center of molecular organic chemistry.

Tribocharging. One example is in tribocharging: that is, the spontaneous separation of electrostatic charge between two materials that occurs on contact (static or dynamic). Tribocharging is responsible for a wide range of phenomena, from the spark at the fingertip on reaching for a doorknob in winter, to dust explosions in grain elevators. For insulating organic materials, essentially all tribocharging involves the transfer of ions (not the transfer of electrons) from one surface to another (Fig. 8) ${ }^{[87]}$.

Correlations between structure and the extent of tribocharging have been convincing in establishing the broad outlines of mechanism in this area, and in allowing it to be used to achieve (for example) Coulombic self-assembly on millimeter-scale objects ${ }^{[8]}$.

Flames. Flames represent another new direction for physical-organic studies. Flames are examples of dissipative systems: that is, of structures or processes whose properties exist solely because there is a flux of free energy out of, or into, the system. Although physical-organic studies of flames as model dissipative systems are just beginning, and although the intellectual structure of physical-organic chemistry is not intended to deal with experimental programs having the characteristics or complexity of dissipative systems (e.g., dynamic self-assembly ${ }^{[89]}$, path selection ${ }^{[90]}$, bistability ${ }^{[91]}$; Fig. 9), the underlying ideas have nonetheless proved invaluable in designing experiments.

\section{Technical Opportunities}

So, at this point in its development, is physical-organic a stable, mature, static field, or is it evolving with time and opportunity? It has, of course, continued to evolve, but with different branches and assuming different characteristics according to the needs of the fields in which the studies occur. There are, however, some common opportunities. A few include these four: 
Computation and Simulation; Theory. These subjects have revolutionized much of chemistry, and will continue to do so, particularly in fields touched by physical-organic strategies. For example, disentangling the contributions of enthalpy and entropy to free energy (a subject that permeates most of science since, the second law of thermodynamics - at least for ensemblesultimately determines what happens) is now, for the first time, beginning to be possible. The opportunity for simulations and theory to rationalize physical-organic approaches is to understand what these areas have to offer, to incorporate them fully into the field, and to frame well-posed questions for theorists and simulators to consider. Computation could be particularly valuable in overcoming a limitation that is common in physical-organic studies: that is, most such studies are designed to isolate one variable, and to study it, alone, to the exclusion of others. There are, of course, many problems for which one must consider the interaction between multiple variables to arrive at a useful conclusion. Simulation and theory —often enabled by computation - have increasingly provided a bridge between one-dimensional, and multi dimensional problems.

Thermochemistry. Thermochemistry remains a critical subject. It is seen as old-fashioned, but it remains the only empirical method for separating enthalpic and entropic contributions to most molecular processes. Automated methods have reduced much of the drudgery of calorimetry, and gone far toward eliminating some of the potential artifacts introduced by van't Hoff analysis, but there remain important, unsolved (and currently insoluble) questions in how to estimate entropy and enthalpy reliably in small samples. Further, there are essentially no methods for obtaining good calorimetric data from the impure samples common in biochemistry. So, there is both an opportunity to use calorimetry and thermochemistry much more broadly than is now common, and an opportunity to improve these technologies substantially (and ideally to introduce fundamentally new methodologies).

New Tools: High-Resolution Structural Analysis. X-ray crystallography has become almost a routine technique. (It is now easier for my students to obtain a crystal structure of a small protein - so long as it crystallizes - than it was for me to obtain an NMR spectrum of ethanol when I was a graduate student.) Neutron diffraction is still a problem (and neutrons have the potential to be enormously useful in understanding the structures of water) because large crystals are required, and because neutrons are scarce. High-resolution electron cryomicroscopy is making astonishing advances in efforts to determine the structures of complex molecules ${ }^{[92,93]}$, but is extraordinarily expensive and complicated. Any consideration of mechanism, or thermodynamics, ultimately must rest on knowing the structures of the reactants and products. Incorporating these tools into the standard armamentarium of physical-organic methodology will broaden its scope.

Single-Molecule Studies, and the Bridge to Thermodynamics. The ability to observe the behaviors and characteristics of individual molecules - whether by spectroscopy, scanning probe microscopy, or some other technique - is a revolutionary change whose importance extends across condensed matter science. For many problems, the results of single-molecule studies will serve as much as a comforting confirmation of existing ideas as it will in providing fundamentally new information. For studies in which the separation of entropy and enthalpy are critical, however, it may do more. The glorious progression from quantum mechanical calculations of single molecules, to statistical mechanical considerations of ensembles of 
molecules, to interpretation of the macroscopic observables provided by thermodynamics has been one of the great accomplishments of molecular science. We do not, however, really know how accurate these steps are in heterogeneous, real systems (e.g., systems containing reactants, solvents or solvent mixtures, and additives). Are there hidden, incorrect, assumptions? Singlemolecule studies may enable us to check the steps in this progression, and to improve or correct as we go along.

\section{Challenges}

And what about the really big problems? Climate instability? Sustainability? Water?

Management of megacities? The nature of life? Is there a role for physical-organic strategies in these areas - areas that depend only in part on what has been considered by chemists to be chemistry? The answer to this question is a matter of opinion, but I would suggest that a physical-organic approach is particularly appropriate as an approach to these subjects - both for its ability to guide thinking about the details of processes involved, and even more for its ability to design experimental programs that survey an unexplored field, and guide research in areas in which there are many complex (and often undefined) variables.

Global Problems. Every aspect of the big global problems - the behavior of atmospheres (including suspended colloids, water droplets, and reactive atmospheric components), the chemical behavior of oceans, the degradation of anthropogenic materials, and many more - is a prototypical physical-organic problem. (One can, for example, make an argument that the atmosphere is a gigantic container filled with particulate microreactors in the form of water droplets and small particles of dust). This type of problem certainly falls in the purview of physical-organic thinking. The most important problem in methods of production of energy that provide alternatives to burning fossil fuels — at least at the moment — is storage. Batteries, interfacial electron-transfer processes, transport of ions across membranes, corrosion and precipitation: all are physical-organic problems. Friction and corrosion both destroy function, and, thus waste energy. The networks of reactions that occur in oceans involve organic, inorganic, biological, photochemical, and geochemical components; physical-organic strategies have historically been good at bridging fields. Managing megacities through appropriate sensor networks; reducing the cost of healthcare; understanding the details of the global fluxes of carbon dioxide and other molecules; all have the potential to benefit from physical-organic strategies.

The Solid State, Especially Heterogeneous Catalysis. Catalysis is so ubiquitous that it is easy to forget, and even easier to ignore how poorly we understand it. The production of fuels and commodity chemicals; the enzyme-catalyzed reactions that provide the basis for life; the reactions in batteries and fuel cells; the geochemical, oceanic, and atmospheric reactions determining global distributions of critical molecules; the disposal of waste in megacities; the production of nitrates for agriculture - all involve processes that are catalyzed heterogeneously, and all are incompletely (at best) understood. Heterogeneous catalysis remains one of the most important, and least understood, areas of chemistry. Enzymatic catalysis in the structured environment of the cell remains mysterious in its ability to support dynamically stable, dissipative, networks (e.g., life). 
In the same vein, separations seem a natural fit with physical-organic strategies, but are seldom studied from that vantage. Purification of water, and separation of methane, $\mathrm{CO}_{2}$, and nitrogen in natural gas, and separation of isotopes are three examples of enormously important problems in separations. Furthermore, issues concerning mechanical structures_corrosion, friction, cracking, oxidative failure, performance of composites - all have components that connect structure and reactivity in ways that physical-organic thinking could help to understand.

Dissipation, and Complex Systems. I have already made a case for the importance of dissipative and complex systems. Another important idea-"emergence," or the observation of phenomena that seem to be inexplicable on the basis of current science-is one that is too complicated, scientifically and semantically, to take up here, and is considered elsewhere; Bob Laughlin, in particular, has discussed the limitations of wholly deterministic approaches to science clearly and provocatively from the vantage of a physicist ${ }^{[94,95]}$. The central point is that in systems that comprise many components interacting strongly (which interactions we may sometimes understand), and many others interacting weakly, non-linearly, and dissipatively (which we almost never fully understand), there are very interesting and important things that happen that we cannot predict accurately, or in some cases (e.g., life, sentience, self-awareness, to take familiar examples with strong ties to molecules and chemistry) even rationalize, based on current science.

Is the science of these types of systems amenable to "physical-organic" approaches, or are they the exclusive purview of physics or neurobiology or economics or whichever established field claims them? (After all, "organic molecules," per se, are often not their exclusive focus, and may be incidental to the core of the problems the systems pose.) I would argue that exploring these areas, and many others - weather, megacities, conflict, patterns of immigration, global management, the generation of clean water and sustainable power-would benefit from the strategies and experimental methods developed in physical-organic science. What "physicalorganic strategy" brings is the idea of synthesis (or preparation, or fabrication, or assembly) of a thoughtfully designed sequence of objects for experimentation to complex problems in a way that helps to test certain classes of hypotheses, and allows the use of physical (and theoretical/computational methods) to generate types of understanding that would otherwise be difficult to obtain. Is this approach unique to "physical-organic chemistry"? Of course not, but it is highly developed there.

These types of experiments are often best for survey work: they may fail in identifying ultimate causes (if, indeed, ultimate causes can ever be identified). That notwithstanding, the simplest experiments in new fields are often among the most valuable, and physical-organic methods have the potential to bring simplicity in experimental design to problems too complex (and too complicated) to approach by the more detailed methods now common in many of those fields. "Correlation" of different dissipative systems may be a start in discovering commonalities, and correlation across processes (with appropriate systematic variations in "structure") is a strength of physical-organic strategies.

One might criticize this approach by saying that "If it's not organic molecules, it's not physical organic chemistry. It's physics (or physical chemistry, or psychology, or economics, or 
whatever.)" That criticism is, in some sense, simultaneously correct and irrelevant. Physicalorganic chemistry, as it took form, fused two previously unrelated subjects - organic synthesis and physical chemistry. The way physical-organic chemists thought about problems was entirely different from the approaches of either synthetic organic chemists or physical chemists (even though all three were formally "chemists." There is no reason to assume that that type of fusion of different fields - one strongly synthetic, and one based on measurement, should not be successful elsewhere. The fields may not be synthetic and physical chemistry, but rather biochemistry and public health, or origin of life and physics, or climate change, analytical chemistry, and the computer science of big data. The techniques will certainly be different, but the strategy and philosophy of an approach based on the marriage of oppositely disposed disciplines would benefit from the experiences and turns of mind of those raised as the offspring.

As I began this essay: "Physical-organic chemistry" is not really about physical chemistry, organic chemistry, or even chemistry. It is a strategy for the design of programs in experimental scientific research ... that offers a general, and remarkably versatile, method for tackling complex problems."

Information. Curiously, "information" has never emerged as a discrete theme in physicalorganic chemistry (or, for that matter, in most of chemistry). It should. Information is now the commodity that connects all of science, and that provides its common vocabulary. As physicalorganic moves to more complex subjects - trying to rationalize molecular recognition in biology and perhaps drug design, the operation of metabolic systems, the chemistry of the atmospherethe problems of manipulating large numbers of data (the "big data" problem) will become an increasing important part of this field (and many others). And of course, the computers, networks, and data-intensive instrumentation on which all fields now depend can operate only with a foundation of information theory. New subjects (e.g., "sparse data" and "data compression ${ }^{[96]}$ ) suggest ways of approaching aspects of problems that were previously intractable.

The subject of information is not totally unfamiliar in physical-organic chemistry, since information and entropy are at least loosely connected (famously, through the work of Claude Shannon $)^{[97]}$, but entropy and information remain semi-hidden variables for much of the field. Among the characteristics of information theory are its focus on strategies for checking errors, and the concept of "surprise:" that is, its focus on recognizing (or extracting) new information or understanding from floods of bits ${ }^{[98-100]}$.

Where, if at all, could ideas about "information" have an influence on molecular science? There are many areas. Three are: understanding i) how the core message system in biology (DNA $\rightarrow$ RNA $\rightarrow$ protein $\rightarrow$ catalysis $\rightarrow$ function $\rightarrow$ metabolism $\rightarrow$ life) might be analyzed in new and intellectually stimulating terms, ii) how errors (a core concern of Shannon, and also the basis for Darwinian evolution) might propagate (for bad or good) through a dissipative system, iii) how to deal with floods of data (in climate instability, drug design, public health, combinatorial methods) and extract useful information from them.

Life, Sentience, and Complex Forms of Self-Assembly. The question "What is life?" is-in my opinion, and the opinions of many others who are (fortunately, since the problem will not be 
solved tomorrow) much younger and smarter than I-perhaps the biggest scientific problem of this century. What is Life? How can it possibly have emerged spontaneously from the chaotic environment of the prebiotic Earth? How did it evolve into sentience and self-awareness? What might be after "Life-as-we-know-it?" These are questions whose answer is Copernican, in the sense that they position human life in the universe.

Are there components of these problems that are best approached using the techniques of physical-organic chemistry? I believe strongly that the answer is "Yes," but remark that the field has not yet (again, in my personal opinion) embraced the very considerable challenges that lie at its core. (It is no surprise that some of the best chemists, and scientists, of the last 100 years have thought deeply about the origin of life, and it still remains, at its center, and unsolved problem $^{[101-103]}$. Thus, for example, one reductionist approach to the cell, and to life, is to say that the cell is "just" a compartmentalized collection of interacting, dissipative, self-assembled reactions that happens - almost unbelievably - to have the characteristics we describe by the adjective "alive." Neither I (nor, I would warrant, anyone else) can claim to understand the relationship between metabolic networks, cellular structure, dissipation, information flow, and thermodynamic properties that make a cell "alive." Further, it is hard to know whether understanding what life is, or how it emerged, is the more difficult problem.

Having said that, every part of the problem (with the possible current exception of how to use "information" in thinking about it) is what physical-organic chemistry has developed to do. "The origin of life" is a perfect fit for physical-organic approaches, and although some areas have made great progress, there are essential parts of the problem where progress has been halting. For example, Joyce, Szostak, and others working "backwards" from current life to infer its origins have made spectacular progress (largely using the idea of an RNA world, in which RNA or a precursor to it provided both "memory" and "catalysis"). Brilliant synthetic work by Eschenmoser, Sutherland, and others have made a strong case that the complex molecules now found in the cell can be synthesized in the laboratory from plausible peribiotic starting materials ${ }^{[104,105]}$. (Whether these synthetic methods apply in the peribiotic environment is another question.) There is, however, still no compelling understanding of how these reactions and molecules began to self-assemble — to put themselves together - to form the first cells, in the chaotic, heterogeneous, peribiotic world ${ }^{[106-108]}$.

This particular problem - the emergence of metabolism, and of self-sustaining, dissipative, densely connected, catalytic molecular systems (whether they resembled current living cells, or tarry cracks in the walls of hot springs) from established chemistry-is the most difficult intellectually I have encountered in my career. It fits the field of physical-organic chemistry perfectly, but will require the incorporation of new experimental and intellectual approaches: genomics, heterogeneous catalysis under unfamiliar conditions, geochemistry, astrochemistry, autocatalysis, biocatalysis, network theory, enzymology, molecular evolution, and especially quantitative methods for analysis of dissipative systems, (most plausibly using kinetic methods developed in chemical engineering). Bringing new ideas into an established field is sometimes difficult.

There is, thus, no question that the origin of life is an excellent "scientific fit" to the field of physical-organic chemistry (broadly defined). Whether the scientific ambition of the field will 
encourage and permit physical-organic chemists to tackle the hardest parts of the problem effectively remains to be seen. The opportunity to take on one of the biggest scientific problems of the century is certainly there. The opportunity and ambition to do so may be a different matter.

\section{Physical-Organic Chemistry: A Swiss Army Knife}

Physical-organic methods provide a strategy for studying complex problems, where the focus is on isolating one type of variation (usually a variation in the structure of the components), and on correlating that variation with some property or function of interest. Historically, physicalorganic chemistry has successfully correlated molecular structure with an astonishingly broad range of properties - from "simple" reactivity, to complex properties such as the folding of proteins and the structure of quantum tunneling barriers. Since all molecules and materials have atomic-level and macro-scale structure, and since the range of properties that can be studied by correlating structure and function, and by rationalizing the correlations, is very large, physicalorganic chemistry can be used in many contexts. More broadly, physical-organic science has the ability to adapt this strategy to a broad range of problems: it is a kind of Swiss army knife: a tool with many uses. It is not, of course, universal, and certainly may not be the best fit for any specific question, but it offers a way to begin to disassemble a very broad range of scientific puzzles.

Acknowledgements. The work I describe here - over several decades - was supported by the National Science Foundation, the Department of Defense, the Defense Advanced Research Projects Agency, the Department of Energy, and the John Templeton Foundation, and the Simons Foundation. The perspective itself was made possible by Chris Flowers. I thank my colleagues Drs. Jerome Fox, Victoria Campbell, K.C. Liao, and Navneet Bhalla for their help in its construction.

\section{References}

[1] R. J. Rogers, H. L. Mitchell, Y. Fujiwara, G. M. Whitesides, J. Org. Chem. 1974, 39, 857858 .

[2] C. L. Hill, J. B. Vander Sande, G. M. Whitesides, J. Org. Chem. 1980, 45, 1020-1028.

[3] L. M. Lawrence, G. M. Whitesides, J. Am. Chem. Soc. 1989, 111, 5405-5412.

[4] P. E. Laibinis, G. M. Whitesides, D. L. Allara, Y.-T. Tao, A. Parikh, R. Nuzzo, J. Am. Chemcial Soc. 1991, 113, 7152-7167.

[5] P. E. Laibinis, C. D. Bain, R. G. Nuzzo, G. M. Whitesides, J. Phys. Chem. 1995, 99, 7663-7676.

[6] C. D. Bain, G. M. Whitesides, J. Am. Chem. Soc. 1988, 110, 3665-3666. 
[7] G. P. Lopez, M. W. Albers, S. L. Schreiber, R. Carroll, E. Peralta, G. M. Whitesides, J. Am. Chem. Soc. 1993, 115, 5877-5878.

[8] C. S. Chen, M. Mrksich, S. Huang, G. M. Whitesides, D. E. Ingber, Science 1997, 276, $1425-1428$.

[9] K. L. Prime, G. M. Whitesides, Science 1991, 252, 1164-1167.

[10] K. L. Prime, G. M. Whitesides, J. Am. Chem. Soc. 1993, 115, 10714-10721.

[11] F. R. F. Fan, J. Yang, L. Cai, D. W. Price, S. M. Dirk, D. V. Kosynkin, Y. Yao, A. M. Rawlett, J. M. Tour, A. J. Bard, J. Am. Chem. Soc. 2002, 124, 5550-5560.

[12] J. C. Love, L. A. Estroff, J. K. Kriebel, R. G. Nuzzo, G. M. Whitesides, Chem. Rev. 2005, $105,1103-1169$.

[13] P. W. Snyder, M. R. Lockett, D. T. Moustakas, G. M. Whitesides, Eur. Phys. J. Spec. Top. 2013, 223, 853-891.

[14] D. J. Raber, R. C. Bingham, J. M. Harris, J. L. Fry, P. V. R. Schleyer, J. Am. Chem. Soc. 1970, 92, 5977-5981.

[15] W. N. Olmstead, J. I. Brauman, J. Am. Chem. Soc. 1977, 99, 4219-4228.

[16] M. L. Chabinyc, S. L. Craig, C. K. Regan, J. I. Brauman, Science. 1998, 279, 1882-1886.

[17] G. M. Whitesides, J. P. Mathias, C. T. Seto, Science 1991, 254, 1312-1319.

[18] J. A. A. W. Elemans, A. E. Rowan, R. J. M. Nolte, J. Mater. Chem. 2003, 13, 2661-2670.

[19] P. W. Snyder, J. Mecinovic, D. T. Moustakas, S. W. Thomas, M. Harder, E. T. Mack, M. R. Lockett, A. Heroux, W. Sherman, G. M. Whitesides, Proc. Natl. Acad. Sci. 2011, 108, 17889-17894.

[20] G. M. Whitesides, Angew. Chemie Int. Ed. 2015, 54, 3196-3209.

[21] J. R. Knowles, Nature 1991, 350, 121-124.

[22] R. H. Grubbs, Angew. Chemie Int. Ed. 2006, 45, 3760-3765.

[23] R. G. Bergman, G. W. Parshall, K. N. Raymond, Biogr. Mem. 1994, 63.

[24] C. Walsh, Enzymatic Reaction Mechanisms, W. H. Freeman, 1979.

[25] E. V. Anslyn, D. A. Dougherty, Modern Physical Organic Chemistry, University Science Books, 1996. 
[26] K. Yates, Hückel Molecular Orbital Theory, Elsevier, 2012.

[27] R. Hoffmann, J. Chem. Phys. 1963, 39, 1397-1412.

[28] G. M. Whitesides, J. San Filippo Jr, E. R. Stredronsky, C. P. Casey, J. Am. Chem. Soc. 1969, 91, 6542-6544.

[29] G. M. Whitesides, C. P. Casey, J. Am. Chem. Soc. 1966, 88, 4541-4543.

[30] M. Hackett, J. A. Ibers, P. Jernakoff, G. M. Whitesides, J. Am. Chem. Soc. 1986, 108, 8094-8095.

[31] G. M. Whitesides, M. Hackett, R. L. Brainard, J. P. P. M. Lavalleye, A. F. Sowinski, A. N. Izumi, S. S. Moore, D. W. Brown, E. M. Staudt, Organometallics 1985, 4, 1819-1830.

[32] M. Hackett, G. M. Whitesides, Organometallics 1987, 6, 403-410.

[33] M. Hackett, J. A. Ibers, G. M. Whitesides, J. Am. Chem. Soc. 1988, 110, 1436-1448.

[34] M. Hackett, G. M. Whitesides, J. Am. Chem. Soc. 1988, 110, 1449-1462.

[35] R. G. Bergman, Pure Appl. Chem. 1981, 53, 161-170.

[36] H. R. Rogers, C. L. Hill, Y. Fujiwara, R. J. Rogers, H. L. Mitchell, G. M. Whitesides, J. Am. Chem. Soc. 1980, 102, 217-226.

[37] H. R. Rogers, R. J. Rogers, H. L. Mitchell, G. M. Whitesides, J. Am. Chem. Soc. 1980, 102, 231-238.

[38] K. S. Root, J. Deutch, G. M. Whitesides, J. Am. Chem. Soc. 1981, 103, 5475-5479.

[39] H. R. Rogers, J. Deutch, G. M. Whitesides, R. J. Rogers, H. L. Mitchell, G. M. Whitesides, C. L. Hill, J. B. Vander Sande, G. M. Whitesides, K. S. Root, et al., J. Am. Chem. Soc. 1980, 102, 226-231.

[40] J. R. Rasmussen, D. E. Bergbreiter, G. M. Whitesides, J. Am. Chem. Soc. 1977, 99, 47464756.

[41] J. R. Rasmussen, E. R. Stedronsky, G. M. Whitesides, J. Am. Chem. Soc. 1977, 99, 47364745 .

[42] S. R. Holmes-Farley, R. H. Reamey, T. J. McCarthy, J. Deutch, G. M. Whitesides, Langmuir 1985, 1, 725-740.

[43] S. R. Holmes-Farley, C. D. Bain, G. M. Whitesides, Langmuir 1988, 4, 921-937. 
[44] F. C. Simeone, H. J. Yoon, M. M. Thuo, J. R. Barber, B. Smith, G. M. Whitesides, J. Am. Chem. Soc. 2013, 135, 18131-18144.

[45] C. A. Nijhuis, W. F. Reus, A. C. Siegel, G. M. Whitesides, J. Am. Chem. Soc. 2011, 133, 15397-15411.

[46] K.-C. Liao, L.-Y. Hsu, C. M. Bowers, H. Rabitz, G. M. Whitesides, J. Am. Chem. Soc. 2015, 137, 5948-5954.

[47] H. J. Yoon, K.-C. Liao, M. R. Lockett, S. W. Kwok, M. Baghbanzadeh, G. M. Whitesides, J. Am. Chem. Soc. 2014, 136, 17155-17162.

[48] J. R. Barber, H. J. Yoon, C. M. Bowers, M. M. Thuo, B. Breiten, D. M. Gooding, G. M. Whitesides, Chem. Mater. 2014, 26, 3938-3947.

[49] C. M. Bowers, K.-C. Liao, T. Zaba, D. Rappoport, M. Baghbanzadeh, B. Breiten, A. Krzykawska, P. Cyganik, G. M. Whitesides, ACS Nano 2015, 9, 1471-1477.

[50] K.-C. Liao, H. J. Yoon, C. M. Bowers, F. C. Simeone, G. M. Whitesides, Angew. Chemie Int. Ed. 2014, 53, 3889-3893.

[51] M. M. Thuo, W. F. Reus, F. C. Simeone, C. Kim, M. D. Schulz, H. J. Yoon, G. M. Whitesides, J. Am. Chem. Soc. 2012, 134, 10876-10884.

[52] H. J. Yoon, N. D. Shapiro, K. M. Park, M. M. Thuo, S. Soh, G. M. Whitesides, Angew. Chemie Int. Ed. 2012, 51, 4658-4661.

[53] H. J. Yoon, C. M. Bowers, M. Baghbanzadeh, G. M. Whitesides, J. Am. Chem. Soc. 2014, $136,16-19$.

[54] C. M. Bowers, K.-C. Liao, H. J. Yoon, D. Rappoport, M. Baghbanzadeh, F. C. Simeone, G. M. Whitesides, Nano Lett. 2014, 14, 3521-3526.

[55] M. Baghbanzadeh, F. C. Simeone, C. M. Bowers, K.-C. Liao, M. Thuo, M. Baghbanzadeh, M. S. Miller, T. B. Carmichael, G. M. Whitesides, J. Am. Chem. Soc. 2014, 136, 16919-16925.

[56] K.-C. Liao, C. M. Bowers, H. J. Yoon, G. M. Whitesides, J. Am. Chem. Soc. 2015, 137, 3852-3858.

[57] A. Salomon, D. Cahen, S. Lindsay, J. Tomfohr, V. B. Engelkes, C. D. Frisbie, Adv. Mater. 2003, 15, 1881-1890.

[58] L. Yuan, N. Nerngchamnong, L. Cao, H. Hamoudi, E. del Barco, M. Roemer, R. K. Sriramula, D. Thompson, C. A. Nijhuis, Nat. Commun. 2015, 6, 1-11. 
[59] V. B. Engelkes, J. M. Beebe, C. D. Frisbie, J. Am. Chem. Soc. 2004, 126, 14287-14296.

[60] G. M. Whitesides, B. Grzybowski, Science 2002, 295, 2418-2421.

[61] J.-M. Lehn, Sci. 2002, 295 , 2400-2403.

[62] J.-M. Lehn, Chem. Soc. Rev. 2007, 36, 151-160.

[63] S. R. Seidel, P. J. Stang, Acc. Chem. Res. 2002, 35, 972-983.

[64] B. Champin, P. Mobian, J.-P. Sauvage, Chem. Soc. Rev. 2007, 36, 358-366.

[65] J. D. Wuest, Acc. Chem. Res. 1999, 32, 81-89.

[66] H. Li, M. Eddaoudi, M. O’Keeffe, O. M. Yaghi, Nature 1999, 402, 276-279.

[67] L. Yang, X. Tan, Z. Wang, X. Zhang, Chem. Rev. 2015, 115, 7196-7239.

[68] T. Aida, E. W. Meijer, S. I. Stupp, Sci. 2012, 335, 813-817.

[69] B. Breiten, M. R. Lockett, W. Sherman, S. Fujita, M. Al-Sayah, H. Lange, C. M. Bowers, A. Heroux, G. Krilov, G. M. Whitesides, J. Am. Chem. Soc. 2013, 135, 15579-15584.

[70] C. T. Seto, G. M. Whitesides, J. Am. Chem. Soc. 1990, 112, 6409-6411.

[71] J. A. Zerkowski, C. T. Seto, D. A. Wierda, G. M. Whitesides, J. Am. Chem. Soc. 1990, 112, 9025-9026.

[72] J. P. Mathias, E. E. Simanek, C. T. Seto, G. M. Whitesides, Angew. Chemie Int. Ed. 1993, $32,1766-1769$.

[73] G. M. Whitesides, J. A. Zerkowski, J. C. MacDonald, D. Chin, in MRS Proc., 1993, 328, 3-14.

[74] G. M. Whitesides, E. E. Simanek, J. P. Mathias, C. T. Seto, D. Chin, M. Mammen, D. M. Gordon, Acc. Chem. Res. 1995, 28, 37-44.

[75] J. C. MacDonald, G. M. Whitesides, Chem. Rev. 1994, 94, 2383-2420.

[76] G. M. Whitesides, V. M. Krishnamurthy, Q. Rev. Biophys. 2005, 38, 385-395.

[77] G. B. Sigal, M. Mammen, G. Dahmann, G. M. Whitesides, J. Am. Chem. Soc. 1996, 118, 3789-3800.

[78] J. E. Kingery-Wood, K. W. Williams, G. B. Sigal, G. M. Whitesides, J. Am. Chem. Soc. 1992, 114, 7303-7305. 
[79] W. J. Lees, A. Spaltenstein, J. E. Kingery-Wood, G. M. Whitesides, J. Med. Chem. 1994, 37, 3419-3433.

[80] K. A. Dill, T. M. Truskett, V. Vlachy, B. Hribar-Lee, Annu. Rev. Biophys. Biomol. Struct. 2005, 34, 173-199.

[81] D. Chandler, Nature 2005, 437, 640-647.

[82] J. Fox, K. Kang, W. Sherman, A. Heroux, G. Sastry, M. Baghbanzadeh, M. Lockett, G. Whitesides, J. Am. Chem. Soc. 2015, 137, 3859-3866.

[83] T. Beuming, Y. Che, R. Abel, B. Kim, V. Shanmugasundaram, W. Sherman, Proteins Struct. Funct. Bioinforma. 2012, 80, 871-883.

[84] T. Young, R. Abel, B. Kim, B. J. Berne, R. A. Friesner, Proc. Natl. Acad. Sci. U. S. A. 2007, 104, 808-813.

[85] R. Abel, T. Young, R. Farid, B. J. Berne, R. A. Friesner, J. Am. Chem. Soc. 2008, 130, $2817-2831$.

[86] T. Beuming, R. Farid, W. Sherman, Protein Sci. 2009, 18, 1609-1619.

[87] L. S. McCarty, G. M. Whitesides, Angew. Chemie Int. Ed. 2008, 47, 2188-2207.

[88] R. Cademartiri, C. A. Stan, V. M. Tran, E. Wu, L. Friar, D. Vulis, L. W. Clark, S. Tricard, G. M. Whitesides, Soft Matter 2012, 8, 9771-9791.

[89] B. a Grzybowski, H. a Stone, G. M. Whitesides, Nature 2000, 405, 1033-1036.

[90] M. J. Fuerstman, P. Garstecki, G. M. Whitesides, Science 2007, 315, 828-832.

[91] J. Fox, G. Whitesides, Proc. Natl. Acad. Sci. 2015, 112, 2378.

[92] B. Liang, Z. Li, S. Jenni, A. A. Rahmeh, B. M. Morin, T. Grant, N. Grigorieff, S. C. Harrison, S. P. J. Whelan, Cell 2015, 162, 314-327.

[93] R. Henderson, Arch. Biochem. Biophys. 2015, 581, $19-24$.

[94] R. B. Laughlin, A Different Universe: Reinventing Physics from the Bottom Down, Basic Books, 2006.

[95] R. B. Laughlin, D. Pines, in Emerg. Contemp. Readings Philos. Sci. (Eds.: M.A. Bedau, P. Humphreys), Bradford Books, 2008.

[96] D. J. Holland, L. F. Gladden, Angew. Chemie Int. Ed. 2014, 53, 13330-13340. 
[97] C. E. Shannon, Bell Syst. Tech. J. 1948, 27, 379-423.

[98] R. P. Feynman, Feynman Lectures on Computation, Westview Press, 2000.

[99] D. G. Luenberger, Information Science, Princeton University Press, Princeton, N.J., 2006.

[100] H. C. von Baeyer, Information, Harvard University Press, Cambridge, M.A., 2003.

[101] A. I. Oparin, Origin of Life, New York, N.Y., 1953.

[102] C. DeDuve, Blueprint for a Cell: The Nature and Origin of Life, Neil Patterson Publishers, Burlington, N.C., 1991.

[103] F. Dyson, Origins of Life, Cambridge University Press, Cambridge, UK, 1985.

[104] A. Eschenmoser, Angew. Chem. Int. Ed. 2011, 50, 12412-72.

[105] B. H. Patel, C. Percivalle, D. J. Ritson, C. D. Duffy, J. D. Sutherland, Nat. Chem. 2015, 7, 301-307.

[106] E. Karsenti, Nat. Rev. Mol. Cell Biol. 2008, 9, 255-62.

[107] L. Dehmelt, P. I. H. Bastiaens, Nat. Rev. Mol. Cell Biol. 2010, 11, 440-452.

[108] S. Soh, M. Byrska, K. Kandere-Grzybowska, B. A. Grzybowski, Angew. Chem. Int. Ed. 2010, 49, 4170-4198.

[109] M. K. Chaudhury, G. M. Whitesides, Science 1992, 256, 1539-1541.

[110] M. D. Dickey, R. C. Chiechi, R. J. Larsen, E. A. Weiss, D. A. Weitz, G. M. Whitesides, Adv. Funct. Mater. 2008, 18, 1097-1104.

[111] S. K. Choi, M. Mammen, G. M. Whitesides, J. Am. Chem. Soc. 1997, 119, 4103-4111. 


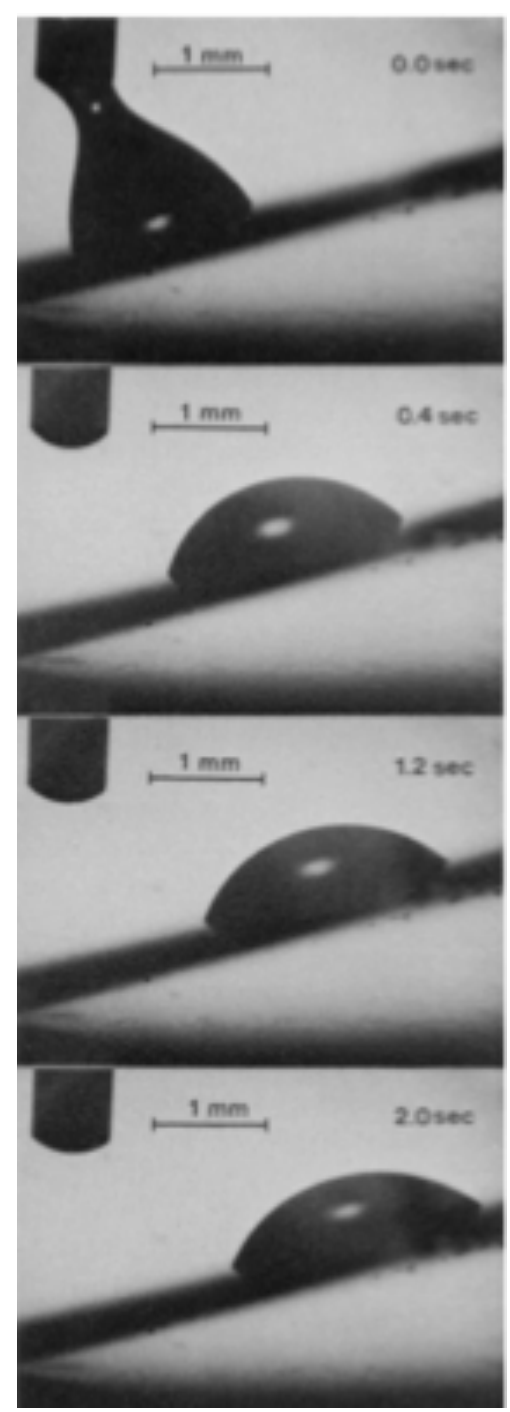

Figure 1. A droplet of water moves uphill—against the field of gravity—along a surface characterized by a gradient in surface free energy ${ }^{[109]}$. At the lower end, the surface is hydrophobic; at the upper, hydrophilic. This process was designed to lower the free energy of the system by moving the droplet from its coverage of a low free-energy surface (lower) to coverage of a higher free-energy surface (upper). The angle of inclination of the surface was $15^{\circ}$, and the volume of the droplet was $\sim 1 \mu \mathrm{L}$. 


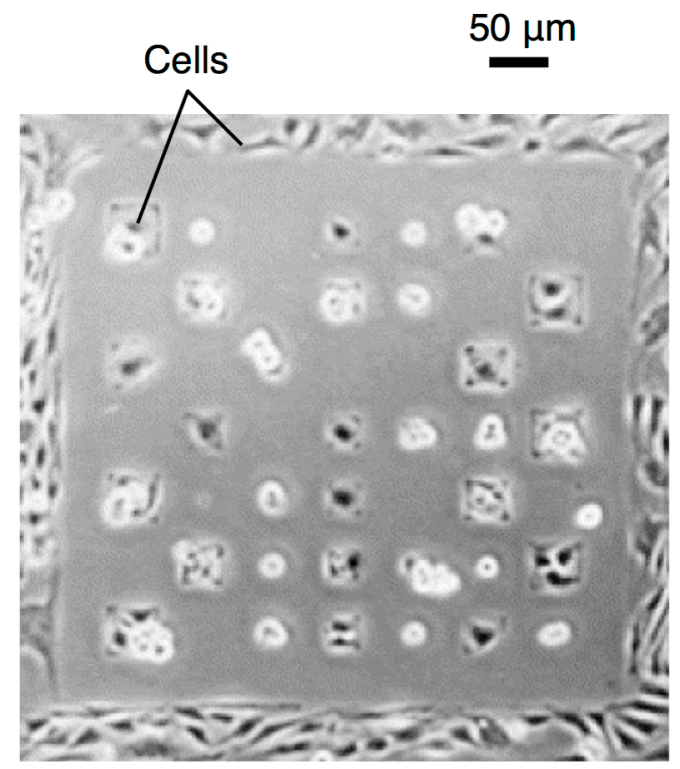

Figure 2. Mammalian cells (bovine capillary endothelial cells) growing on an interface comprising a gold film (as a support) and a SAM patterned into protein adsorbing (small hydrophobic squares, and square boundary) and protein-resistant (continuous background surface) regions. The hydrophobic squares adsorbed proteins from the culture medium, and cells attached to (and in some squares, divided on) these regions. The background region - the region to which cells did not adsorb - was a SAM terminated in oligo(ethylene glycol) groups. These $(\mathrm{OEG})_{\mathrm{n}}$-covered regions do not adsorb most proteins significantly, and thus do not allow cells to attach. SAMs allow physical-organic designs to be integrated into studies of the biochemistry of attachment of proteins and cells to surfaces. This figure is reproduced with permission from reference ${ }^{[85]}$. 


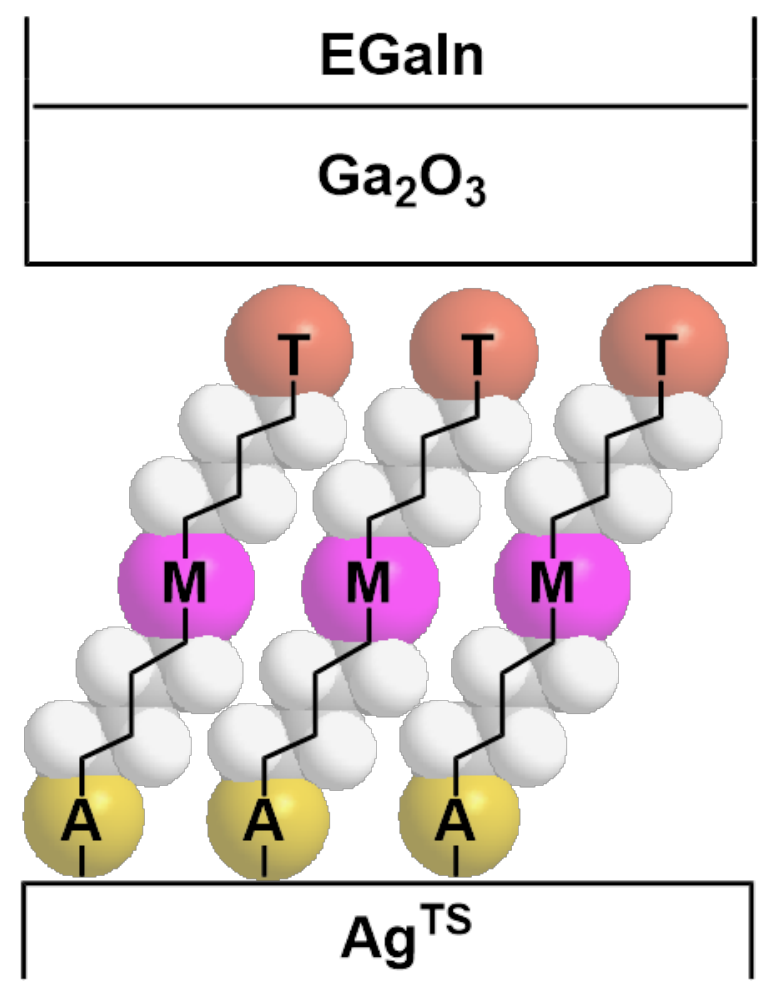

Figure 3. Schematic representation of molecular junctions with the structure $\mathrm{Ag}^{\mathrm{TS}} / \mathrm{A}\left(\mathrm{CH}_{2}\right)_{\mathrm{n}} \mathrm{M}\left(\mathrm{CH}_{2}\right)_{\mathrm{m}} \mathrm{T} / / \mathrm{Ga}_{2} \mathrm{O}_{3} / \mathrm{EGaIn}$, where $\mathrm{Ag}^{\mathrm{TS}}$ is template-stripped silver and EGaIn is a eutectic alloy of gallium and indium, covered by a native skin of gallium oxide ${ }^{[110]}$. " $\mathrm{A}$ " is the "anchoring" group attaching the SAM to the surface of $\mathrm{Ag}^{\mathrm{TS}}$; " $\mathrm{T}$ " is the "terminal" group of the SAM and usually in van der Waals contacts (indicated as "//") with $\mathrm{Ga}_{2} \mathrm{O}_{3} / \mathrm{EGaIn}$; "M" is the middle group connecting the anchoring group $\mathrm{A}$ and the terminal $\mathrm{T}$ with the poly(methylene) spacers $n$ and $m$. 


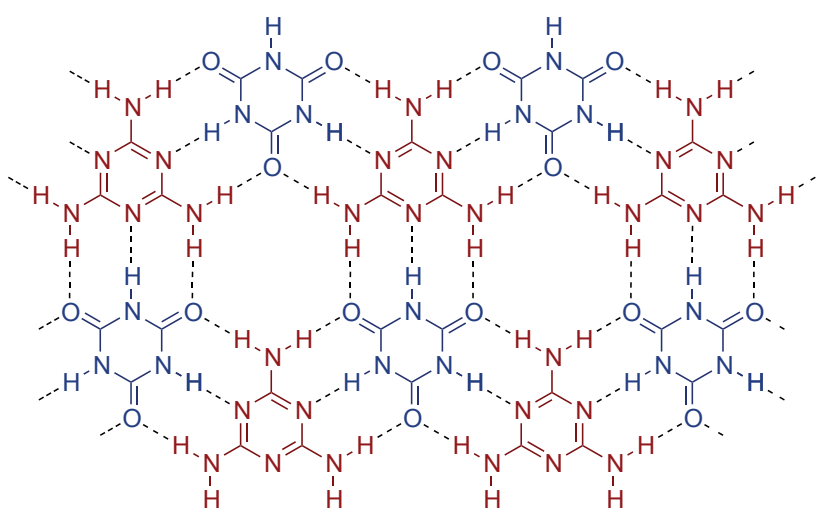

Hydrogen bonded self-assembled network
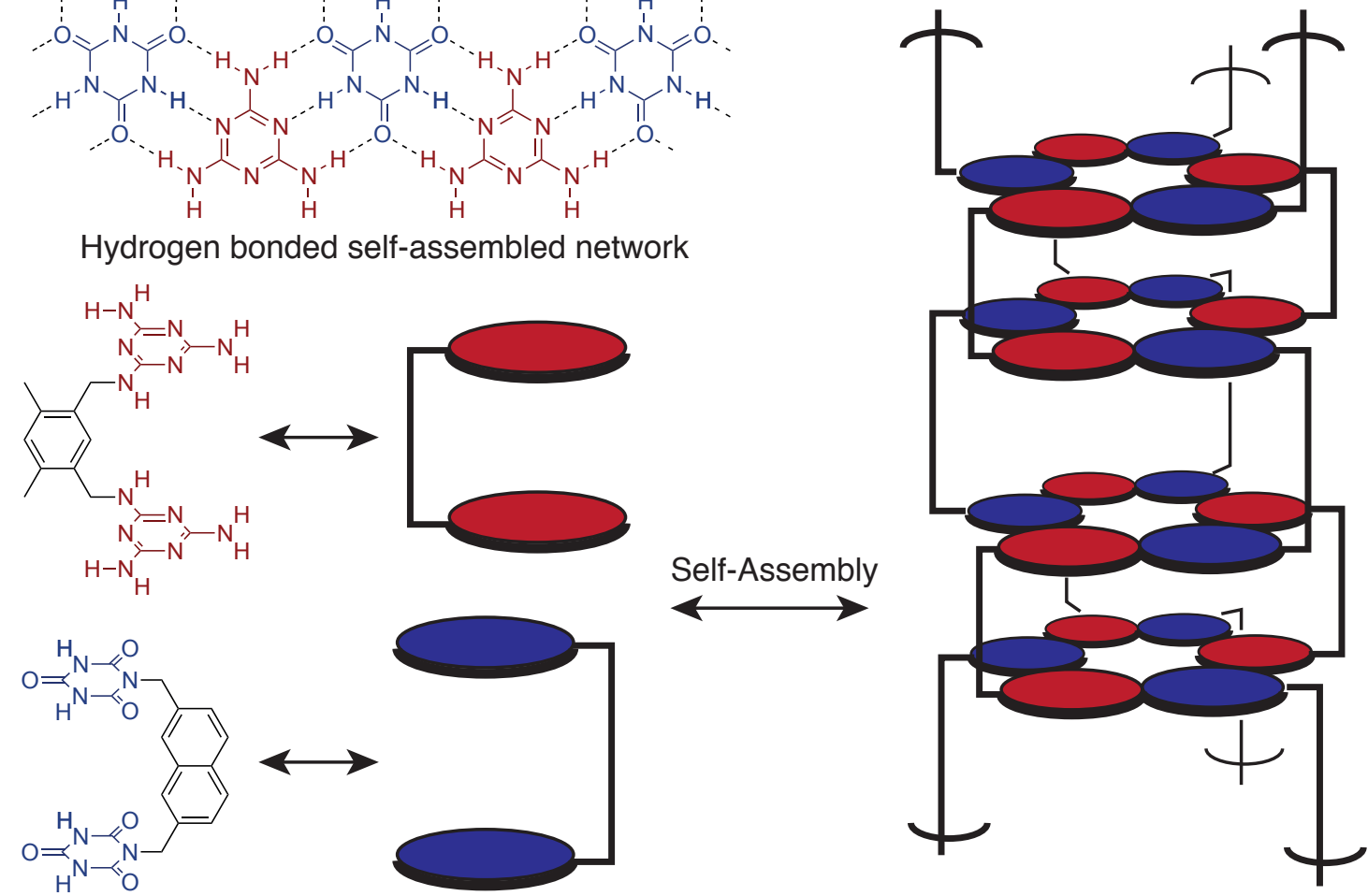

Figure 4. (Upper): Schematic representation of the extended C3 planar lattice in the solid state by a 1:1 mixture of melamine and cyanuric acid ${ }^{[86]}$. This self-assembled structure is very stable, and it has served as the basis for physical-organic studies of designed self-assembly in the solid state. (Lower): An extended rod structure formed in the solid state by self-assembly by bivalent derivatives of melamine and cyanuric acid ${ }^{[75]}$. Red = melamine; blue = cyanuric acid. 


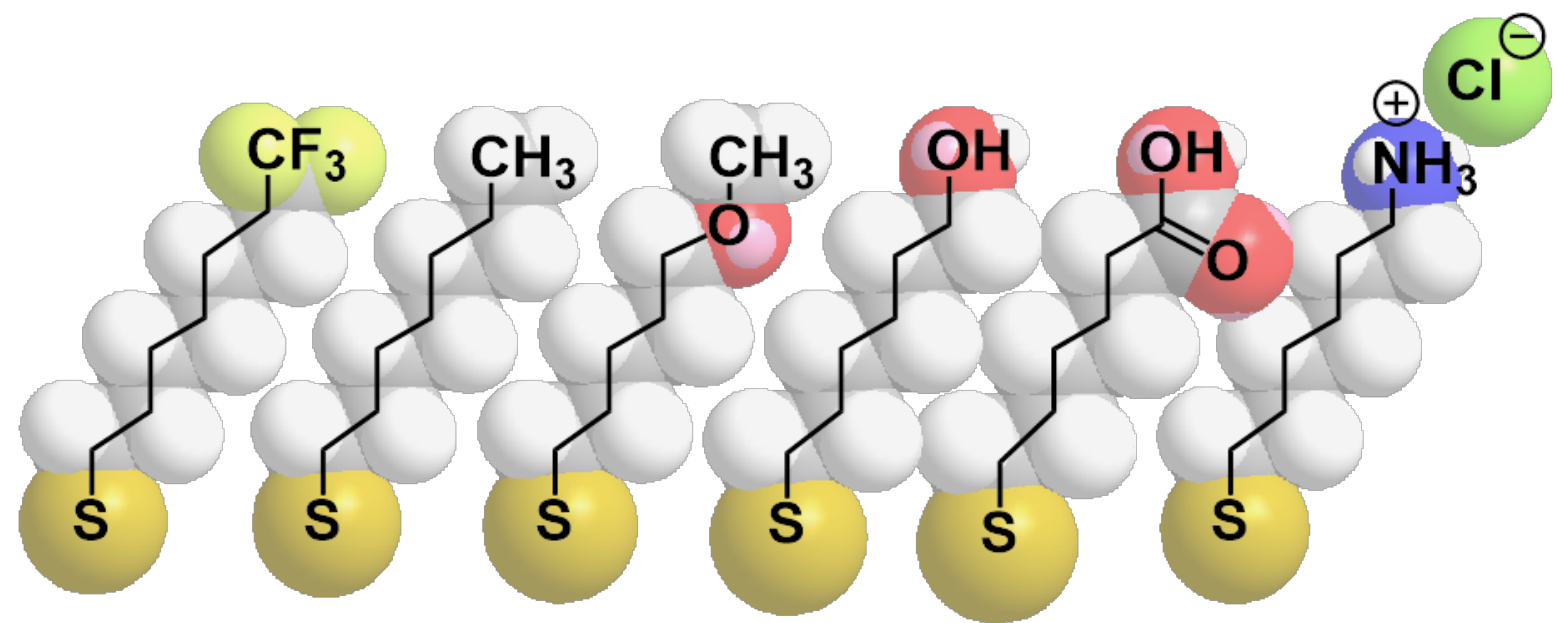

Figure 5. Structure of molecules representative of those that can be included in well-ordered SAMs, with terminal groups ranging from very hydrophobic $\left(-\mathrm{CF}_{3}\right)$ to very hydrophilic ($\left.\mathrm{NH}_{3}{ }^{+} \mathrm{Cl}^{-}\right)$. A general introduction to SAMs is provided in reference ${ }^{[12]}$. 


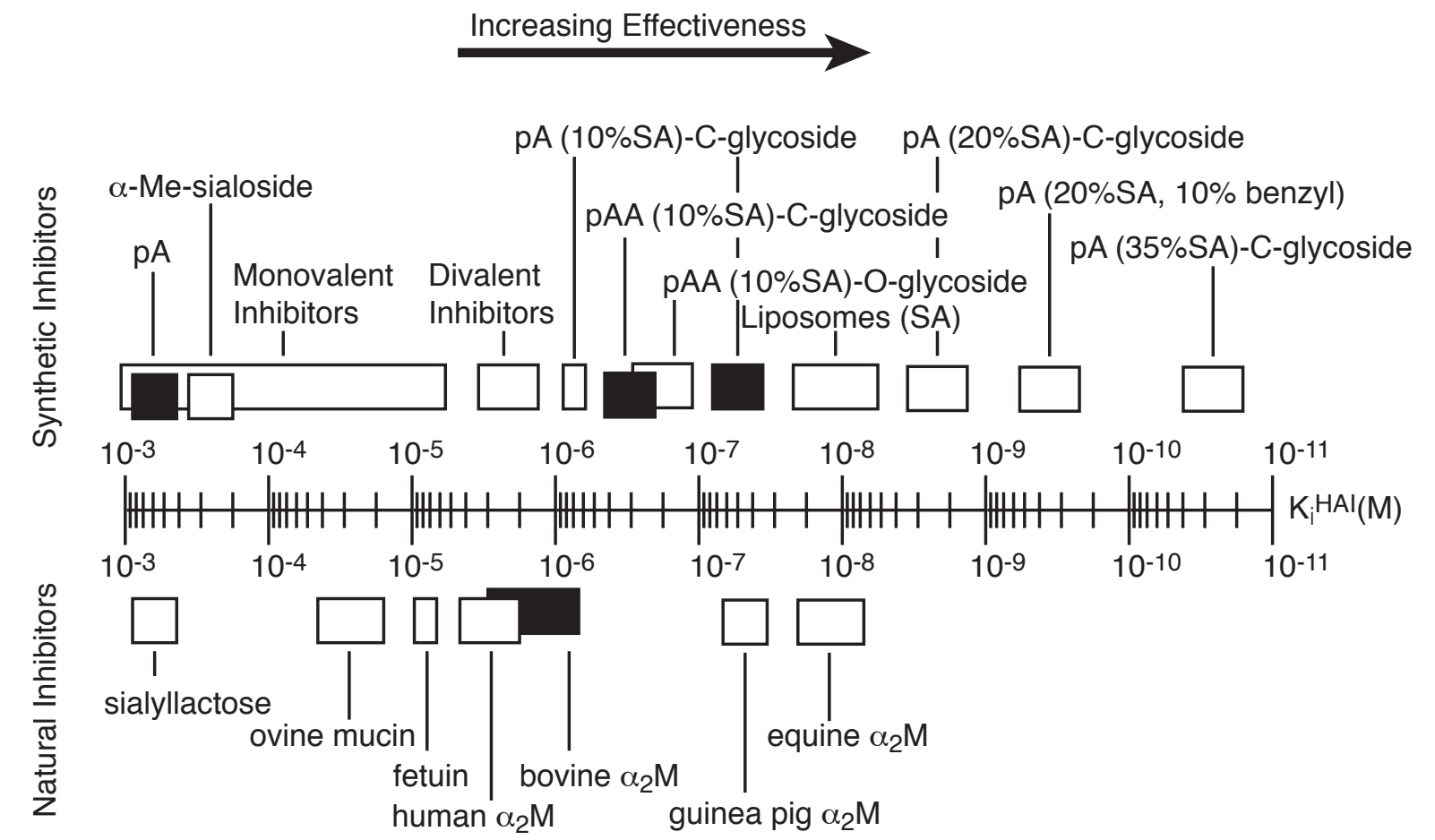

Figure 6. Constants $\mathrm{K}^{\mathrm{HAI}}$ describing the inhibition, by a derivative of sialic acid, of the clumping of chicken erythrocytes caused by influenza virus. (This clumping process is believed to mimic an early step in the entry of influenza virus into mammalian cells - that is, the association of the virus with the cell via attachment of one or more trimers of hemagglutinin on the surface of the virus to sialic acid groups on the surface of the cell). Each sialic acid included in a copolymer of acrylamide and acrylamide covalently linked to sialic acid is $10^{9}$ more effective at inhibiting cell clumping than is $\alpha$-methylsialoside. ( $\alpha_{2} \mathrm{M}$ is $\alpha_{2}$ Macroglobulin.) We elaborate on the use of sialosides in the design of polyvalent inhibitors of the influenza-mediated clumping of cells in reference ${ }^{[111]}$. 

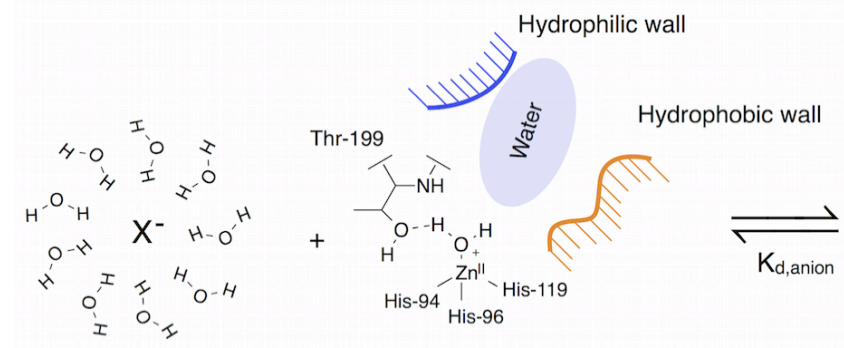

Solvated Anion

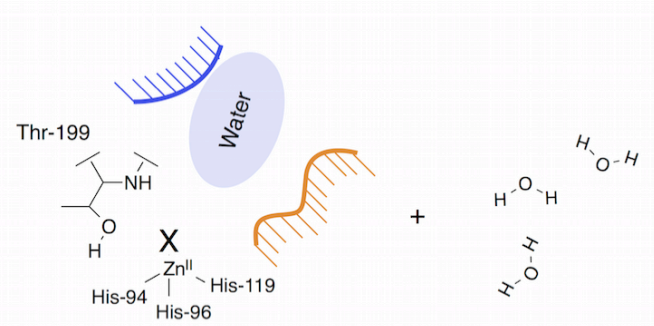

Molecules of water formerly solvating the anion and/or the active site

Figure 7. Anion-protein association in aqueous solution. Weakly hydrated Hofmeister anions can associate with the $\mathrm{Zn}^{2+}$ cofactor of human carbonic anhydrase II (HCAII). The free energy of binding is influenced by rearrangements in the water surrounding the anion and filling the binding pocket of the protein. This figure is reproduced with permission from reference ${ }^{[82]}$. 


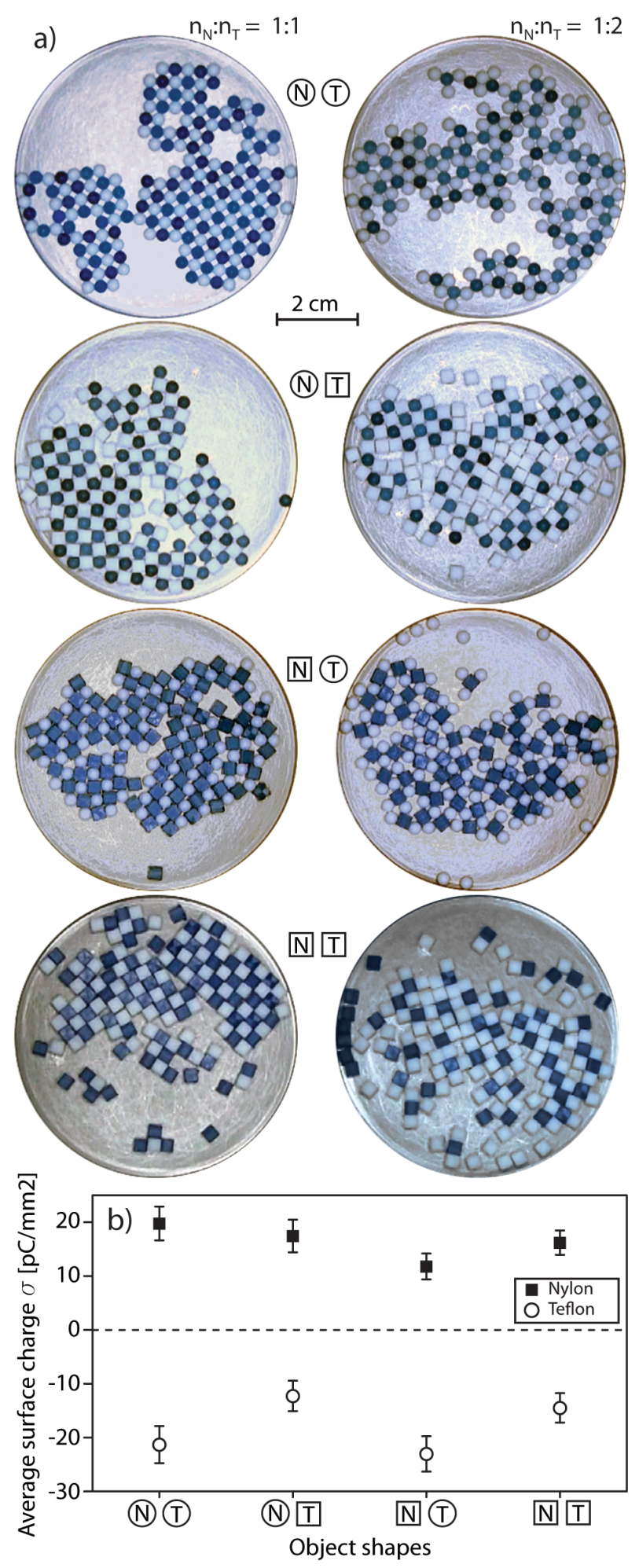

Figure 8. Coulombic self-assembly of millimeter-scale objects fabricated in Nylon (blue) and Teflon (white). These assemblies are supported in a dish lined with paper. When agitated in a way that causes them to move on the paper (by shaking), they charge triboelectrically: Teflon develops a negative charge; Nylon, a positive charge. They crystallize in more-or-less regular 
lattices and aggregates, and the processes they follow offer an approach to simulating (and visualizing) the nucleation of crystals of ionic salts (e.g., $\mathrm{NaCl}$ ). The assembly process is dissipative: agitation is necessary to develop the different electrostatic charges, and to allow the particles to collide and rearrange to form crystals and structured aggregates. The magnitude of the charge on the particles, at steady state, during triboelectrification, represents a balance between charge separation (by partitioning of differently charged ions to the surfaces of the two polymers) and dissipation of charge to the atmosphere (at high levels of charge, plausibly in a corona discharge). This Figure is reproduced with permission from reference ${ }^{888}$. 


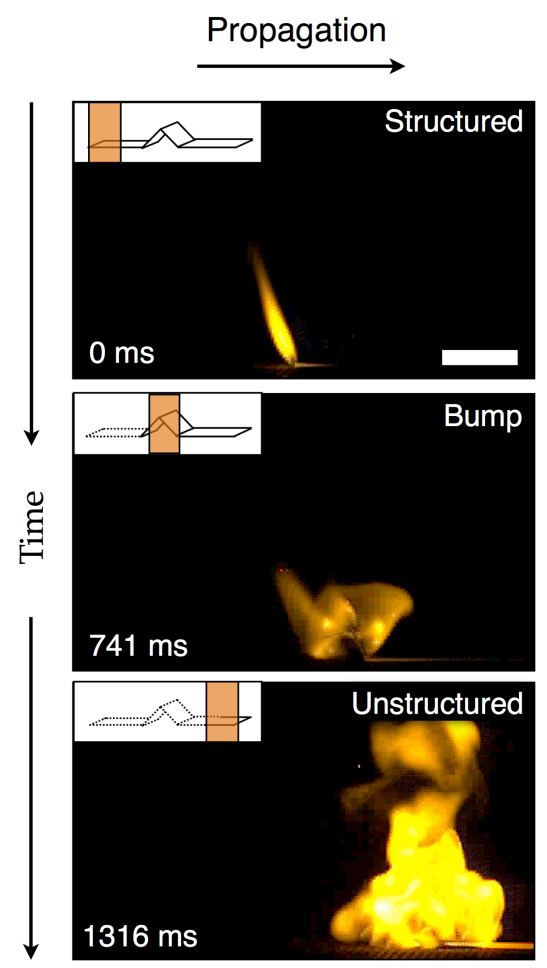

Figure 9. A flame propagating along a strip of nitrocellulose. In this system, flames can travel with one of two stable modes of propagation: a slow, structured mode (top) and a rapid, unstructured mode (bottom) ${ }^{[91]}$. Upon encountering a bump in the strip (middle), flames can transition between these modes; the image shows a structured-to-unstructured transition, but the reverse is also possible. By permitting the examination of patterns in flame dynamics (e.g. subtle movements of the flame) under different environmental conditions (e.g. angle of the nitrocellulose strip, temperature of the surface supporting the strip), this system revealed that structured flames exhibit detectable systems of critical slowing down (i.e., the slowed recovery of multistable systems from perturbations as those systems approach tipping points) under conditions where structured-to-unstructured transitions are likely to occur. This result suggests that the onset of conflagrations in large-scale natural fires may have early warning signals. 